\title{
Queen mating frequencies and genetic relatedness between workers in the hornet Vespa ducalis (Hymenoptera: Vespidae)
}

\author{
Jun-ichi Takahashi, ${ }^{1,4, *}$ Shin-ichi Akimoto, ${ }^{1}$ Eisuke Hasegawa ${ }^{2}$ and Jun Nakamura ${ }^{3}$ \\ ${ }^{1}$ Laboratory of Systematic Entomology, and ${ }^{2}$ Laboratory of Animal Behavior, Department of Ecology and Systematics, Graduate \\ School of Agriculture, Hokkaido University, Sapporo 060-8589, Japan \\ ${ }^{3}$ Honeybee Science Research Center, Tamagawa University, Machida, Tokyo 194-8610, Japan \\ (Received 1 February 2002; Accepted 22 May 2002)
}

\begin{abstract}
Vespa ducalis is a monogynous hornet with an annual life cycle. Its colonies are the smallest in the genus Vespa. Generally, it is thought that the number of queen matings and colony size are positively correlated, so we analyzed the queen mating number and genetic relatedness between workers of $V$. ducalis using microsatellite DNA markers. We examined foundress queens and 20 workers from each of 20 colonies. All colonies were found to have one queen inseminated by one male. The genetic relatedness between workers was $0.724 \pm 0.0029$ (mean \pm SE), which is not significantly different from the expected value of 0.75 for full sisters. This result suggests a possible conflict in male production between queens and workers based on kin selection prediction. Therefore, we performed microsatellite analysis of 400 males from 20 colonies to verify whether males are derived from either queens or from workers. No males could be assigned to workers developed ovaries were not found in a total of 880 mature workers. These results strongly suggest that queens dominate production of males in $V$. ducalis colonies.
\end{abstract}

Key words: Vespa ducalis, microsatellites, relatedness, mating number, worker reproduction

\section{INTRODUCTION}

Kin selection theory is central to the issue of social evolution in Hymenoptera (Crozier and Page, 1985). Hamilton (1964) proposed that kin selection plays a significant role in higher genetic relatedness between colony members. In monogynous hymenoptera, when foundress queens mate with multiple males, sister-sister relatedness decreases with queen mating frequency. Therefore, low intracolonial genetic relatedness does not favor the evolution of worker sterility in Hymenoptera (Hamilton, 1964; Pamilo, 1991). However, multiple matings by monogynous queens has been reported in honeybees, yellowjackets, and leafcutter ants (Boomsma and Ratnieks, 1996; Crozier and Pamilo, 1996; Foster and Ratnieks, 2001; Strassmann, 2001). Several hypotheses have been proposed for the evolution and maintenance of multiple matings in social Hymenoptera in connection with kin selection including reduction in queen and worker conflict over sex ratio; reduction in the production of diploid males (Page, 1980; Page and
Metcalf, 1982); increase in reproductive fitness due to storage of more sperm (Cole, 1983; Fjerdingstad and Boomsma, 1998); increase in resistance to parasites and pathogens (Sherman et al., 1988; Schmid-Hempel, 1998); high genetic diversity between workers within a colony due to multiple matings (Keller and Reeve, 1994).

Generally, it is thought that the number of queen matings and colony size are positively correlated (Crozier and Pamilo, 1996). V. ducalis is a highly eusocial wasp with the smallest number of colony workers in the genus Vespa (Matsuura and Yamane, 1984). Therefore, the small colony size of $V$. ducalis suggests a bias towards single matings by foundress queens of this species and a resultant high degree of kin relatedness leading to queenworker conflict over male production due to kin selection with some male production by workers (Ratnieks, 1988). To test these predictions, we investigated the number of queen matings, genetic relatedness between workers, and male production in $V$. ducalis using four microsatellite DNA markers and a dissection method.

\footnotetext{
* To whom correspondence should be addressed at: E-mail: tkhsj1am@agrs.tamagawa.ac.jp

${ }^{4}$ Present address: Laboratory of Entomology, Department of Agriculture, Graduate School of Agriculture, Tamagawa University, Machida, Tokyo, 194-8610 Japan
} 


\section{MATERIALS AND METHODS}

Sample collection. In September of 1999, 20 wild colonies of $V$. ducalis were collected over an area of about $70 \mathrm{~km}^{2}$ from a forest outside Noda City in Chiba Prefecture, Japan $\left(13^{\circ} 20^{\prime} \mathrm{N}\right.$, $\left.20^{\circ} 45^{\prime} \mathrm{E}\right)$. Collection was performed by blocking the nest entrance at night and introducing approximately $10 \mathrm{ml}$ of diethyl ether into the nest. All individuals were collected and taken alive to the laboratory where the absence or presence of the foundress queen was confirmed. For microsatellite DNA analysis, 20 workers and 20 males per colony were preserved in $99 \%$ ethanol and frozen at $-20^{\circ} \mathrm{C}$. The remaining adult workers were stored at $-20^{\circ} \mathrm{C}$ to check development of the ovary.

DNA extraction and microsatellite DNA analysis. Microsatellite DNA analysis was conducted by using four microsatellite primers (Hasegawa and Takahashi, in press). DNA extraction was based on the method of Walsh et al. (1991). Template DNA was extracted from thorax muscle tissues of individuals by boiling macerated tissue in $400 \mu \mathrm{l}$ of $5 \%$ Chelex resin for $2 \mathrm{~h}$. All polymerase chain reactions (PCR) were performed in a total volume of $10 \mu \mathrm{l}$, which contained $1.0 \mu \mathrm{l}$ (about $10 \mathrm{ng}$ ) of template DNA, $0.2 \mu \mathrm{M}$ of primer, $400 \mu \mathrm{M}$ of dNTP mix, $1.0 \mu \mathrm{l}$ of $10 \times$ reaction buffer, $1.5 \mathrm{mM} \mathrm{MgCl}_{2}$, and 0.05 units Taq polymerase (Takara). The primer pair was Texas red end-labeled. All PCR reactions were performed with the following cycle parameters: after one denaturing step of $3 \mathrm{~min}$ at $94^{\circ} \mathrm{C}$, the samples were processed through 30 cycles consisting of $30 \mathrm{~s}$ at $94^{\circ} \mathrm{C}, 30 \mathrm{~s}$ at 52 to $58^{\circ} \mathrm{C}$, and $30 \mathrm{~s}$ at $72^{\circ} \mathrm{C}$. The last elongation step was lengthened to $10 \mathrm{~min}$. The PCR products were denatured with $6 \%$ polyacrylamide sequence gels and then analyzed by an SQ-5500 auto sequencer (Hitachi).

Data analysis. We estimated the regression relatedness $(b)$, inbreeding $(F)$, and allele frequencies using the Relatedness 4.2 computer program (Goodnight and Queller, 1994). Colonies were equally weighed, and standard errors and $t$-test were calculated by jackknifing over colonies (Queller and Goodnight, 1989). Estimates of pedigree relatedness $\left(g_{w w}\right)$ were inferred from worker genotypes over the four loci for each colony (Boomsma and Ratnieks, 1996):

$$
g_{w w}=0.25+0.5 \sum P_{i}^{2}
$$

where $\sum P_{i}$ is the average of the sums for the squared proportional $i$ th fathering males (Boomsma and Van der Have, 1999). The effective mating frequency $\left(M_{e}\right)$ was calculated according to Starr (1984):

$$
M_{e}=1 / \sum_{i=1}^{k} P_{i}^{2}
$$

where $P_{i}$ is the proportional contribution of the $i$ th fathering male, and $k$ is the number of fathering males for each colony. Estimates of queen mating frequencies are affected by two sources of errors: non-sampling and non-detection (Boomsma and Ratnieks, 1996). The probability of non-sampling of paternal genotypes is high when the number of workers analysed is small, because paternal genotypes are rare when insufficient offspring are screened. We assumed that intracolonial paternity was kept of acceptable levels by the analysis of 20 workers from each colony. For the 20 workers analyzed, the probability of non-sampling such a rare male is negligibly small. Rare males have a small effect on effective mating frequency, and non-sampling errors were calculated according to Foster et al. (2000). If workers produce a proportion $\chi$ of the males, the probability of not sampling any workerproduced males is $(1-\chi)^{N_{a}}$. Here $N_{a}$ is the total number of assignable males in a sample. We used the procedure of Foster et al. (1999) to estimate the non-detection error probability. One patriline is indistinguishable from another when the genetic marker loci have only low levels of polymorphism. The second possible error is a non-detection error. The probability of two patrilines in a population having identical genotypes at all analysed loci, and thus having indistinguishable offspring is:

$$
d_{p}=\prod\left(\sum q_{i}^{2}\right) j
$$

where, the non-detection error value of population $\left(d_{p}\right)$ and $q_{i}$ denote the allele frequencies at each of $j$ loci (Boomsma and Ratnieks, 1996). However, these estimates assume that paternal and maternal transmitted alleles can be distinguished. The maternal genotype was inferred from the offspring genotypes when sampling of the mother queen was 
impossible. The emergence probability of male offspring of workers was calculated according to the method of Foster et al. (2000). The male offspring of workers can be detected when $1 / 2$ of the alleles are transmitted from workers. For unlinked loci (four loci per colony), the total number of assignable males in a sample $\left(N_{a}\right)$ can be estimated from the formula of Foster et al. (2000):

$$
N_{a}=\sum_{j}^{n}\left(1-\prod_{i}^{l_{j}}\left(1-0.5 p_{i j}\right)\right) N_{j}
$$

where, $l_{j}$ is the number of loci, $N_{j}$ is the number of males analysed for the $j$ th of $n$ colonies, and $p_{i j}$ is the proportion of informative worker genotypes at the $i$ th loci of the $j$ th colony. Here $p_{i j}$ were weighted equally and workers of all genotypes were regarded as having no differences in reproduction rate.

Dissection of workers' ovaries. The workers of 20 colonies were checked for ovarian development. A total of 880 adult workers were selected randomly from up to $90 \%$ of all workers for each of the 20 colonies. The degree of ovarian development was scored by the index of Yamane (1974). All samples were compared to the ovarian condition of three laying workers from two queenless colonies collected in August from the same area.

\section{RESULTS}

\section{Variation of microsatellite loci of Vespa ducalis}

Microsatellite DNA analysis was conducted using four primers designed from $V$. mandarinia. High allelic variation was observed in the 20 colonies (Table 1). The VMA-1, VMA-3, VMA-7 and VMA-8 loci had allelic variations of 4, 4, 3 and 4 , respectively. The mean expected heterozygosity for all loci was 0.66 .

\section{Mating structure}

Foundress queens were found in 13 of the 20 collected colonies. Each queen in the 13 colonies had been inseminated by a single male (Table 2). The inbreeding coefficient was significantly different from zero $F=-0.0063$ over four loci as expected for a random mating system. The mating structure of $V$. ducalis is explained by one queen mating with one male. The non-detection error of the colony level $\left(d_{c}\right)$ ranged from 0.0010 to 0.0012 , and population level $\left(d_{p}\right)$ over the 20 colonies was very low 0.001 (Table 2). Therefore, second paternity was detected only $0.1 \%$ of the time, suggesting no effect on the results.

\section{Genetic relatedness between intracolonial mem- bers}

The regression coefficient for relatedness between nestmate workers in the 20 colonies was $0.724 \pm 0.0029$ (mean $\pm S E$ ), which is not significantly different from the expected value of 0.75 for full sisters. While the pedigree relatedness between nestmate workers in the 20 colonies was 0.750 , the estimate agrees well with the regression coefficient for relatedness (Table 2). These result is strongly suggestive of monogyny in the 20 examined colonies.

Table 1. Number of alleles ( $n$ ), allele frequency and expected heterozygosity $\left(H_{E}\right)$ of four microsatellite loci for $V$. ducalis

\begin{tabular}{llccccc}
\hline & & \multicolumn{5}{c}{ Allele frequency } \\
\cline { 3 - 6 } Locus & $n$ & \multirow{2}{*}{$H_{E}$} \\
& & $\mathrm{a}$ & $\mathrm{b}$ & $\mathrm{c}$ & $\mathrm{d}$ & \\
\hline VMA-1 & 4 & 0.338 & 0.232 & 0.215 & 0.215 & 0.70 \\
VMA-3 & 4 & 0.271 & 0.200 & 0.371 & 0.158 & 0.72 \\
VMA-7 & 3 & 0.527 & 0.334 & 0.139 & & 0.54 \\
VMA-8 & 4 & 0.234 & 0.238 & 0.226 & 0.302 & 0.67 \\
Mean & 3.75 & & & & & 0.66 \\
\hline
\end{tabular}

Table 2. Mean of mating frequency, relatedness between workers and inbreeding coefficient, non-detection error and non-sampling error of 20 colonies of $V$. ducalis

\begin{tabular}{|c|c|c|c|c|c|}
\hline \multirow{2}{*}{$\begin{array}{l}\text { Mating } \\
\text { number } \\
\text { (mean)* }^{*}\end{array}$} & \multicolumn{2}{|c|}{ Relatedness (mean \pm SE) } & \multirow{2}{*}{$\begin{array}{l}\text { Inbreeding* } \\
(\text { mean } \pm S E)\end{array}$} & \multirow{2}{*}{$\begin{array}{c}\text { Non-detection } \\
\text { error } \\
(\text { mean } \pm \mathrm{SE})\end{array}$} & \multirow{2}{*}{$\begin{array}{c}\text { Non-sampling } \\
\text { error } \\
\text { (mean } \pm \mathrm{SE})\end{array}$} \\
\hline & Pedigree* & Regression & & & \\
\hline 1.00 & 0.750 & $0.724 \pm 0.0029$ & $-0.0063 \pm 0.160$ & $0.001 \pm 0.0002$ & $0.001 \pm 0.0001$ \\
\hline
\end{tabular}

* Asterisks were calculated except for unrelated workers. 


\section{Male production and worker oviposition}

In all 20 colonies, all males had alleles found only in the genotypes of queens at all loci. The number of adult workers of 20 colonies was $44.45 \pm 20.31$ (mean $\pm S D)$. This result is not different from past data (Matsuura and Yamane, 1984). The 880 dissected workers from the 20 colonies did not show ovarian development. Therefore, all males were clearly the offspring of queens. The number of assignable male $\left(N_{a}\right)$ was 257 . This is equivalent to a probability of less than $7.6 \%$ of missing a worker contribution to male production greater than $1 \%$ (Fig. 1).

\section{Usurpation of $\boldsymbol{V}$. ducalis}

Multiple matrilines were detected in three of the 20 colonies where some mature workers did not have the queen's genotype, suggesting queen usurpation (Table 3).

\section{DISCUSSION}

Our research suggests that a $V$. ducalis queen mates with only one male and that each colony is headed by one queen. The mean mating frequency is very low at 1.0 , because the sperm of only one

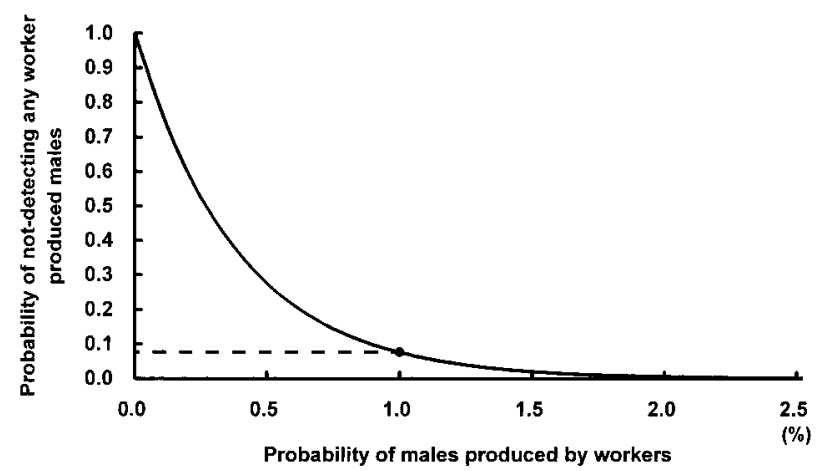

Fig. 1. Male non-detection error of $V$. ducalis. The vertical axis indicates probability of not detecting any worker produced males when assignable males $\left(N_{a}\right)$ is 257 (detail see, Foster et al., 2000). male is used to fertilize all the eggs of one colony. These results are consistent with our expectations. Matsuura and Yamane (1984) reported monogyny as typical of temperate hornets and hornet queens are typically observed performing one mating with one male. Using microsatellite DNA analysis, Foster et al. (1999) found an effective mating number of 1.13 in $V$. crabro, with a multiple mating queen frequency of $24 \%$ (Foster et al., 1999, 2000). The basic kin structure of the $V$. ducalis colonies in this study was monogynous, one queen mating with one male (Table 2).

Multiple matrilines in workers was found in three colonies (Table 3 ). If multiple matrilines are found, we can make two predictions accounting for the source of these matrilines. Because worker drift is very low in the genus Vespa (Matsuura and Yamane, 1984), multiple matrilines of these colonies probably resulted from nest usurpation. Successful usurpation was found in only 2 out of 33 colonies of $V$. crabro in Britain (Foster et al., 2000), while we found 3 possible cases of usurpation in 20 colonies of $V$. ducalis. Therefore, the two Vespa show similar levels of intraspecific usurpation.

The pedigree relatedness between nestmate workers in $V$. ducalis was estimated to be 0.75 , while that for $V$. crabro was estimate to be 0.69 by Foster et al. (1999). To assess the degree of worker reproduction, we dissected up to $90 \%$ of adult workers from each colony. Hornet workers have no ability to mate (Matsuura and Yamane, 1984), but a few workers in queenless colonies can develop the ability to lay male eggs (Yamane, 1974; Matsuura and Yamane, 1984). No workers with ovarian development comparable to ovaries in laying workers in queenless colonies were found in a total of 880 workers for the 20 colonies examined. Moreover, despite genetic analysis of 20 males in each colony, we found no alleles for the queen's mates. These results suggest that male production in queenright colonies of $V$. ducalis is dominated by queens, and

Table 3. Genotype of the usurpation colony in $V$. ducalis. Genotype of unrelated workers are underlined

\begin{tabular}{|c|c|c|c|c|c|c|c|c|}
\hline \multirow{2}{*}{$\begin{array}{l}\text { Microsatellite loci } \\
\text { Colony code }\end{array}$} & \multicolumn{2}{|c|}{ VMA-1 } & \multicolumn{2}{|c|}{ VMA-3 } & \multicolumn{2}{|c|}{ VMA-7 } & \multicolumn{2}{|c|}{ VMA-8 } \\
\hline & Queen & Workers & Queen & Workers & Queen & Workers & Queen & Workers \\
\hline Vdu-9910 & $\mathrm{bb}$ & $18 \mathrm{ab}, \underline{1 \mathrm{ac}}, \underline{1 \mathrm{~cd}}$ & $\mathrm{bc}$ & $10 \mathrm{bc}, 8 \mathrm{cc}, \underline{2 \mathrm{aa}}$ & $\mathrm{ac}$ & $13 \mathrm{aa}, 7 \mathrm{ac}$ & $\mathrm{ab}$ & $6 \mathrm{ad}, 14 \mathrm{bd}$ \\
\hline Vdu-9912 & $\mathrm{ab}$ & 10aa, 9ab, 1미 & ac & $9 \mathrm{ab}, 11 \mathrm{bc}$ & aa & $17 \mathrm{aa}, 3 \underline{\mathrm{bb}}$ & $\mathrm{ac}$ & $7 \mathrm{ad}, 13 \mathrm{~cd}$ \\
\hline Vdu-9956 & aa & $17 \mathrm{ab}, \underline{1 \mathrm{bc}}, \underline{2 \mathrm{ac}}$ & ac & $6 \mathrm{ac}, 11 \mathrm{cc}, \underline{3 \mathrm{bb}}$ & aa & $20 \mathrm{aa}$ & bc & $13 b b, 7 b c$ \\
\hline
\end{tabular}


that worker oviposition only occurs when the queen dies.

These results show that the kin structure of $V$. ducalis consists of monogynous, single mated queens and random breeding. The kin selection theory predicts that conflict occurs between queens and workers over male production because the coefficient of relatedness of workers to intracolony males is highest for their own offspring $(r=1 / 2)$, next highest for the male offspring of a full sister $(r=3 / 8)$, next for the male offspring of a mother queen $(r=1 / 4)$, and lowest for the male offspring of a half sister $(r=1 / 8)$. As a result, worker reproduction might be expected to evolve in monogynous Hymenoptera (Ratnieks, 1988). However, we found no evidence of male offspring from workers in the 20 colonies of $V$. ducalis studied. Compared to other eusocial Hymenoptera, the mating frequency and genetic structure of the genus Vespa has been little studied (Foster and Ratnieks, 2001; Strassmann, 2001). Recently, the mating frequency of $V$. crabro was also found by microsatellites analysis (Foster et al., 1999).

So why don't workers of $V$. ducalis and $V$. crabro lay male eggs? Further research on the kin structure and male production of other Vespa species might help clarify the conflict between the queen and workers over male production. The mature colony size of $V$. ducalis is the smallest in the genus Vespa (Matsuura and Yamane, 1984) but two closely related species in the tropics of the $V$. tropica group, $V$. tropica and $V$. philippinensis have much larger colonies (2,500 to 6,000 cells) than $V$. ducalis (200 cells) (Kojima, 1982; Matsuura and Yamane, 1984; Matsuura, 1990; Archer, 1991). Cole (1983) suggested that the number of queen matings and colony size of eusocial Hymenoptera are positively correlated. Colony size of the hornet varies more than other eusocial Hymenoptera. Especially, the $V$. tropica group is shown to be monophyletic by a phylogenetic analysis (Archer, 1994). Therefore, this group is suitable for testing on these predictions. If both number of queen matings and worker oviposition are strongly correlated to colony size, perhaps $V$. tropica and $V$. philippinensis show higher levels of multiple matings than $V$. ducalis and worker male production may occur. This is a subject for future research.

\section{ACKNOWLEDGEMENTS}

We thank two anonymous referees for insightful comments on the manuscript. We thank Prof. Masami Sasaki and Dr. Masato Ono of the University of Tamagawa for providing the hornet-proof suits and helpful suggestions for this work.

\section{REFERENCES}

Archer, M. (1991) Taxonomy and bionomics of the Vespa tropica group (Hym., Vespinae). Entomol. Month. Mag. 127: 225-232.

Archer, M. (1994) A phylogenetic study of the species of the genus Vespa (Hymenoptera: Vespidae). Entomol. Scand. 24: 469-478.

Boomsma, A. F. G. and Van der Have (1999) Queen mating and paternity variation in the ant Lasius niger. Mol. Ecol. 7: 1709-1718.

Boomsma, J. J. and F. L. W. Ratnieks (1996) Paternity in eusocial Hymenoptera. Phil. Trans. R. Soc. Lond. B 351: 947-975.

Cole, B. J. (1983) Multiple mating and the evolution of social behavior in the Hymenoptera. Behav. Ecol. Sociobiol. 12: 191-201

Crozier, R. H. and R. E. Page (1985) On being the right size: male contributions and multiple mating in the social Hymenoptera. Behav. Ecol. Sociobiol. 18: 105-115.

Crozier, R. H. and P. Pamilo (1996) Evolution of Social Insect Colonies. Sex Allocation and Kin Selection. Oxford Univ. Press, Oxford. 306 pp.

Fjerdingstad, E. J. and J. J. Boomsma (1998) Multiple mating increases the sperm stores of Atta colombica leafcutter ant queens. Behav. Ecol. Sociobiol. 42: 257-261.

Foster, K. R. and F. L. W. Ratnieks (2001) Paternity, reproduction and conflict in vespine wasps: a model system for testing kin selection predictions. Behav. Ecol. Sociobiol. 50: $1-8$.

Foster, K. R., F. L. W. Ratnieks and A. F. Raybould (2000) Do hornets have zombie workers? Mol. Ecol. 9: 735-742.

Foster, K. R., P. Seppä, F. L. W. Ratnieks and P. A. Thorén (1999) Low paternity in the hornet Vespa crabro indicates that multiple mating by queens is derived in vespine wasps. Behav. Ecol. Sociobiol. 46: 252-257.

Goodnight, K. F. and D. C. Queller (1994) Relatedness 4.2. Goodnight Software, Houston, Texas.

Hamilton, W. D. (1964) The genetical theory of social behaviour. I, II. J. Theor. Biol. 7: 1-52.

Hasegawa, E. and J. Takahashi Microsatellite loci for genetic researches of the hornets Vespa mandarinia and their related species. Mol. Ecol. Notes (in press)

Keller, L. and H. Reeve (1994) Genetic variability, queen number, and polyandry in social Hymenoptera. Evolution 48: 694-704.

Kojima, J. (1982) The genus Vespa in the Philippines (Hymenoptera, Vespidae). Kontyū 50: 434-444.

Matsuura, M. (1990) Biology of three Vespa species in central Sumatra (Hymenoptera, Vespidae). In Natural History of Social Wasps and Bees in Equatorial Sumatra (S. F. Sakagami, R. Ohushi and D. W. Roubik eds.). Hokkaido Univ. 
Press, Sapporo, pp. 113-124.

Matsuura, M. and S. Yamane (1984) Biology of the Vespine Wasps. Hokkaido Univ. Press, Sapporo. 429 pp.

Page, R. E. Jr. (1980) The evolution of multiple mating behavior by honey bee queens (Apis mellifera L.). Genetics 96: 263-273.

Page, R. E. Jr. and R. A. Metcalf (1982) Multiple mating, sperm utilization, and social evolution. Am. Nat. 119: 263-281.

Pamilo, P. (1991) Evolution of colony characteristics in social insects. I. Sex allocation. Am. Nat. 137: 83-107.

Queller, D. C. and K. F. Goodnight (1989) Estimating relatedness using genetic markers. Evolution 46: 258-275.

Ratnieks, F. L. W. (1988) Reproductive harmony via mutual policing by workers in eusocial Hymenoptera. Am. Nat. 132: 217-236.

Schmid-Hempel, P. (1998) Parasites and Social Insects.
Princeton Univ. Press, Princeton, NJ. 409 pp.

Sherman, P. W., T. D. Seeley and H. K. Reeve (1988) Parasites, pathogens and polyandry in social hymenoptera. Am. Nat. 131: 602-610.

Starr, C. K. (1984) Sperm competition, kinship, and sociality in the aculeate Hymenoptera. In Sperm Competition and the Evolution of Animal Mating Systems (R. L. Smith ed.). Academic Press, Orlando, pp. 427-464.

Strassmann, J. (2001) The rarity of multiple mating by females in the social Hymenoptera. Insectes Soc. 48: 1-13.

Walsh, P. S., D. A. Metzger and R. Higuchi (1991) Chelex 100 as a medium for simple extraction of DNA for PCRbased typing from forensic material. Biotechniques 10 : 506-513.

Yamane, S. (1974) Observations on an orphan nest of Vespa simillima Smith (Hymenoptera, Vespidae). Konty $\bar{u}$ 42: 404-415. 